\title{
Analysis of gas expander substituting for natural gas valve in a natural gas pressure regulating station
}

\author{
LI Xiaxi ${ }^{1}$, Xiong Yaxuan ${ }^{2 *}$, Xing Linlin ${ }^{1}$, LI Bo $^{2}$, ZHANG Hui ${ }^{1}$, QIAN Di ${ }^{1}$, Liu \\ Rong $^{2}$
}

${ }^{1}$ Beijing Gas Group Co., Ltd. Beijing 100035; 2 Beijing university of Civil Engineering and Architecture, Beijing 100044

Keywords: natural gas; pressure regulator; gas expander; outlet temperature; preheating load; hydrate

Abstract: a pressure regulator is an essential equipment during delivering natural gas to consumers with the help of pipe lines at present, but the potential pressure energy of high-pressure natural gas is not recovered. So a gas expander is employed to replace some regulators to recovery pressure energy during the expansion of high-pressure natural gas as possible and transfer to mechanical work. And then a numerical model is established based on the First Law and second Law of thermodynamics to analyze the variation of gas expander outlet temperature, the variation of preheating load of natural gas and the influence of the isentropic efficiency of gas expander during the expansion of natural gas. The results show that applications of the gas expander lead to a much lower outlet temperature of natural gas than that of regulators, which aggravate the formation of natural gas hydrate and so preheating the natural gas is necessary before natural gas entering the gas expander to prevent from the formation of natural gas hydrate. The gas expander brings about a much lower specific enthalpy of natural gas than that of regulators at outlet and then the preheating load increases to 3 times of itself. For different type of gas expanders the preheating load of natural gas increases linearly with the isentropic efficiency of the gas expander while the outlet temperature of natural gas reduces linearly with the isentropic efficiency. For a determined turbine gas expander the preheating load of natural gas increases approximately linear with the increase of natural gas volume flow lower than its rated volume flow, while the influence of volume flow larger than its rated volume flow on preheating load natural gas is very low.

\section{Introduction}

With the rapid economy development and the severe situation of energy saving and emission reduction in China, the consumption of natural gas increases rapidly every year, and that has exceeded 181.6 billion $\mathrm{m}^{3}$ in 2014. Natural gas is delivered from gas field "West East Gas Transmission" and "Shanxi-Beijing pipe lines", or gasification station of LNG(liquefied natural gas) with the pressure of $6 \sim 10 \mathrm{MPa}$. Then it multilevel-depressure through the natural gas pipe lines and delivers to the residents and industrial gas users. At present, the pressure regulator and throttle are the major equipments for high-pressure natural gas regulating system, there is rich pressure energy $^{[2][3]}$ will be wasted during pressure regulating. A gas expander can recovery pressure energy $^{[1]-[3]}$ during the expansion of high-pressure natural gas as possible and transfer to mechanical work. According to the statistics ${ }^{[3]}$, Beijing Gas Group Co. Ltd. supplies 10.5 billion $\mathrm{m}^{3}$ natural gas only in 2014, there would be generate more than 180 million degrees of power every year if the gas expander is used to recover the pressure energy. The power generation will be a much bigger in China, it will achieve the objective of energy-saving, emission-reduction and save a lot of traditional fossil energy, such as coal, oil and natural gas. But there are also some problems will happen when the gas expander is set into the system, for example the phenomenon of the freezing on equipments and pipe lines will be more serious ${ }^{[4]-[9]}$, and power generation instability because of the fluctuations in natural gas flows, and so on. And all such problems will influence normal work of the station and caused potential safety hazard for pipe lines. But there will be a good economic benefit if suitable measures be taken. Recently, theoretical study about use of natural gas pressure energy just begin ${ }^{[11]-[16]}$, though US and Canada developed such engineering practice about pressure energy from $1980 \mathrm{~s}^{[4]}$. It was developed a little late in China, and it's There is less research on the 
theoretical study, experiment and engineering practice ${ }^{[17]-[20]}$.

At background of energy-saving ,emission-reduction and what described above, this article analyses the problems on gas expander substituting for natural gas valve in a natural gas pressure reducing station, and give some feasible advises.

\section{Establish numerical model of gas pressure regulating and expansion power generation system}

It will compare and analyze the system consists of the gas expander and the pressure regulator, because the gas expansion does not own the function of regulator independent, the natural gas pressure energy power generation system as shown in Figure 1. The gas expander uses natural gas pressure to electric power generation, natural gas pressure regulation of partly naturl gas and outlet gas regulator by the pressure regulator, two preheaters are used to preheat natural gas of two lines. In order to calculate and analyze, assume the same gas mass flows through the pressure regulator and gas expander, the same gas temperature be done by the 1\# natural gas heater and the 2\# natural gas heater, and the same temperature of natural gas through the pressure regulator and gas expander.

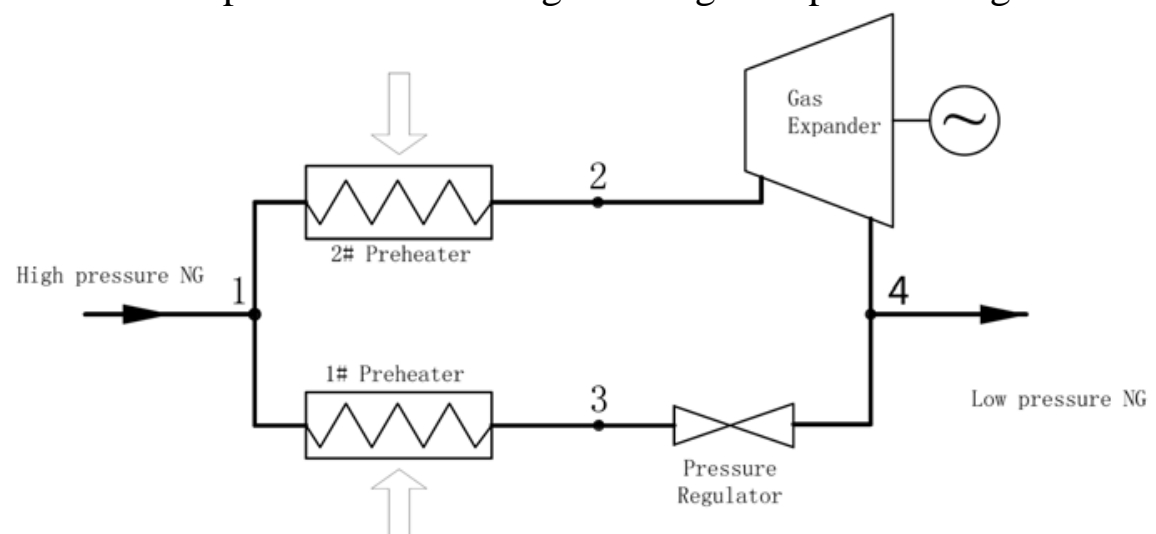

Figure 1: natural gas pressure regulating system based on natural gas pressure energy expansion electric power generation

In the system shown in Figure 1, with ignoring the heat transfer of the pressure regulator, the heat loss of heater $1 \#$ and resistance of pipelines and heat exchanger, the process in preheater is an isobaric heat transfer, and pressure process in gas pressure regulator is an isenthalpic throttling processes by the first law of thermodynamics.

For 1\# preheater

For gas pressure regulator

$$
h_{3}=h_{1}+\dot{Q}_{1}
$$

$$
h_{4}=h_{3}
$$

Formula of 1\# preheater load from formula (1) and formula (2)

$$
\dot{Q}_{1}=h_{4}-h_{1}
$$

Natural gas in gas expander to expand acting, regardless of expansion machine body heat transfer, heater 2\# heat loss, pipeline and heat resistance of heat exchanger, preheater is an isobaric heat transfer and expansion machine in the compression process is an adiabatic expansion pressure, first and second laws of thermodynamics.

For 2\# preheater

For gas expander

$$
h_{2}=h_{1}+\dot{Q}_{1}
$$

$$
w_{t}=\left(h_{2}-h_{4}\right) \eta
$$

Formula of 2\# preheater load from formula (4) and formula (5) 


$$
\dot{Q}_{2}=h_{4}+\frac{w_{t}}{\eta}-h_{1}
$$

In the formula, $h_{1}, h_{2}, h_{3}$ and $h_{4}$ are the enthalpy $(\mathrm{kJ} / \mathrm{kg})$ of natural gas in the point of $1,2,3$ and $4 ; \dot{Q}_{1}$ and $\dot{Q}_{2}$ are the heat load of 1 \#preheater and 2\#preheater, $w_{t}(\mathrm{~W})$ is the outlet work of gas expander, $\quad \eta$ is the isentropy efficiency of gas expander.

In fact, natural gas is mixture gases ,and the main component is alkanes. Among these alkanes, the methane is accounted for the vast majority and the other parts are a small amount of hydrocarbon such as ethane, propane and butane, carbon dioxide and nitrogen which change the thermophysical property of pure methane, it will be calculated and analyzed a kind of natural gas (mole ratio of methane $87.2 \%$, ethane $7.6 \%$, propane $3.1 \%$, n-butane $0.5 \%$, isobutane $0.8 \%$,nitrogen $0.4 \%$, pentane $0.2 \%$ and isopentane $0.2 \%$ ) in this paper ${ }^{[4]}$, the thermophysical property of mixture gases calculated by theory method ${ }^{[21]}$, enthalpy is the function of temperature and pressure, so we can get the natural gas temperature from the enthalpy and pressure of natural gas.

$$
T=f(h, p)
$$

The mathematical model is built and calculated by EES software.

\section{Discussion}

\subsection{Influence on gas expander for gas hydrate formation}

In condition of the regular pressure of natural gas, if here is a certain amount of moisture in the natural gas, so when the temperature is lower than a certain value, the natural gas hydrate will generate, which consist of natural gas and water, the equilibrium phase diagram of temperature and pressure is shown in Figure 2. In Figure 2 , when the temperature lower, the natural gas hydrate will be more stability and the rate of it generate will be faster in a pressure.

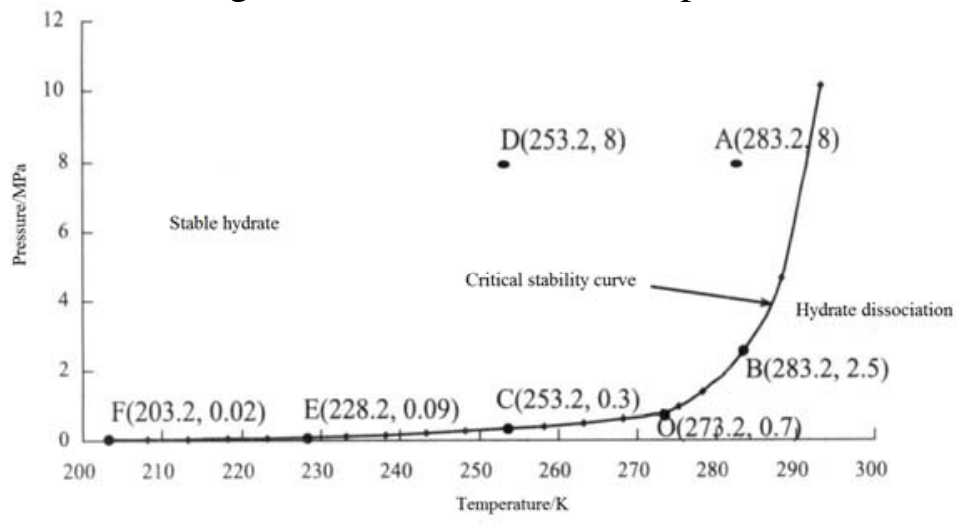

Figure 2 equilibrium phase diagram of a kind of natural gas hydrate temperature and pressure

For natural gas pressure regulating station, when the gas temperature and pressure to meet the conditions state above, in the outlet of pressure regulating valve will generate natural gas hydrates and blocked pressure regulating valve or pipelines and equipments, occur the heave or freezing and blocking accident, and even cause serious natural gas accidents. For pressure regulating valve, due to the relatively low temperature natural gas in the upper reaches in winter, the possibility of generating natural gas hydrate in the outlet of pressure regulating valve is very high. Since 2010,the phenomenon like freezing and blocking happened in Beijing Xiaotangshan A-high-pressure station,Caiyu station, Daxing south station, Xishatun, Tongzhou A-high-pressure station, Weishanzhuang box, Daxing vehicle section box, Machikou I, Machikou II, Miaocheng A-high-pressure station, Fule B-high-pressure pressure regulating box, Yanmen Cun pressure regulating station and so on, some gas stations or pressure regulating box even happened five times such accidents within a year. In this case, if heat the natural gas before it flows into pressure regulating valve, control the gas temperature higher than the temperature of natural gas hydrates on 
the outlet, and it will avoid the potential safety hazard caused of natural gas hydrates generation.

But for a pressure regulating station, inlet and outlet pressure of natural gas is constant, shown in Figure 2, the natural gas outlet temperature is the key factor to determine the generation of natural gas hydrate. For the natural gas with $4.0 \mathrm{MPa}$ inlet pressure and $0^{\circ} \mathrm{C}$ inlet temperature to the flow of natural gas, regulating the gas pressure from the $4.0 \mathrm{MPa}$ to $1.6 \sim 2.5 \mathrm{MPa}$, the gas expander is a single screw gas expander with 60\% isentropic efficiency, figure 3 shows that the outlet pressure variation curve of gas outlet temperature and temperature difference between inlet and outlet .

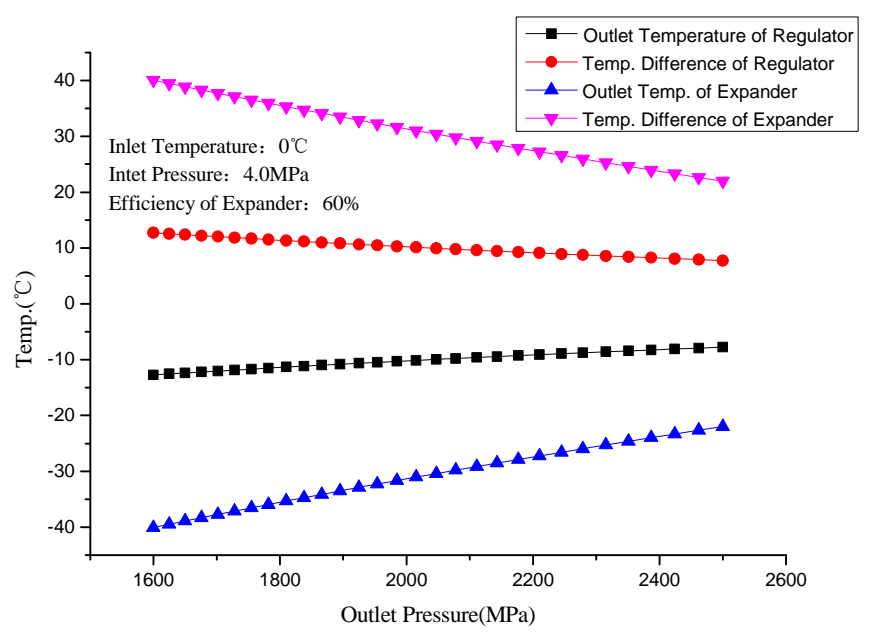

Figure 3 the outlet temperature and inlet and outlet temperature of the pressure regulating valve /gas expander the outlet pressure change

In Figure 3, for the pressure regulator, it can be seen that the absolute value of the gradient of the curve for difference in temperature between outlet and outlet is smaller, and the minimum temperature of natural gas is only $-12.7^{\circ} \mathrm{C}$, the difference in temperature between outlet and inlet outlet is variation in the range of $7.8 \sim 12.5^{\circ} \mathrm{C}$, when the inlet temperature of pressure regulator inlet temperature of gas is $0^{\circ} \mathrm{C}$, and the gas pressure variation in the range of $1.6 \sim 2.5 \mathrm{MPa}$, which the pressure regulator inlet and outlet temperature is linear with the outlet pressure. And for gas expander, gradient of the curve is larger than the pressure regulator. The minimum outlet temperature of natural gas is $-40^{\circ} \mathrm{C}$, the maximum outlet temperature of natural gas is $-22^{\circ} \mathrm{C}$, which is much lower than outlet temperature of pressure regulator $\left(-12.7^{\circ} \mathrm{C}\right)$; In the meantime, the difference in temperature of gas expander's outlet and inlet at the range of $22 \sim 40^{\circ} \mathrm{C}$, the outlet temperature of gas expander is linear reduction with the outlet pressure.

Through the above analysis, it can be found whether pressure regulator or gas expander, the outlet temperature of natural gas is linear increasing with the outlet pressure, that is the higher outlet pressure, higher outlet temperature when the system is in the determined inlet temperature and pressure; And the difference in temperature of inlet and outlet natural gas is linear increase with the increase pressure, that is the higher pressure, the smaller difference in temperature. For a certain component of natural gas, there will appear formation of natural gas hydrate on the outlet of pressure regulator when the pressure regulator is used to adjust the pressure, the outlet temperature will lower when use gas expander replace the pressure regulator, this will aggravate formation of natural gas hydrate, which leads to freezing and blocking the pipelines and equipments. Therefore, It must increase the inlet temperature of natural gas by preheating, or dry natural gas to reduce the water content of natural gas by using dry method.

\subsection{Effect of gas expander on preheating load of natural gas}

From the existing treatment technology for natural gas, it is an ideal project to prevent the formation of gas hydrate from natural gas preheating. The relationship between the heat load and the outlet pressure, the heat load and the natural gas flow, and the variation of heat load and the outlet temperature with the isentropic efficiency of the gas expander is shown in Figure 4-6. 


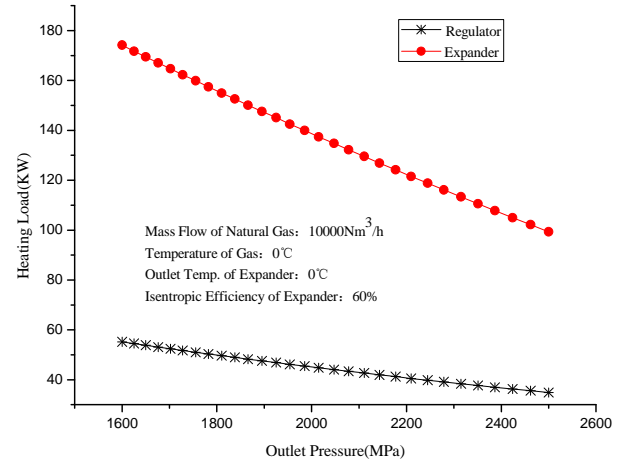

Fig. 4 Variation of natural gas heating load with the outlet pressure

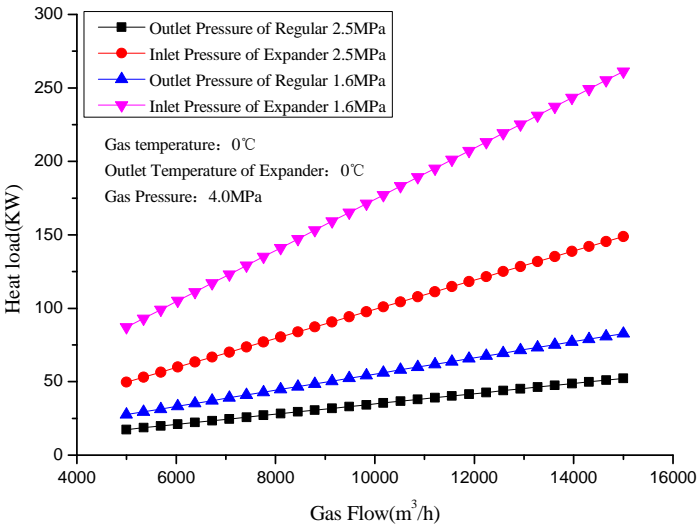

Fig. 5 Variation of natural gas heating load with the flow

As Figure 4 shown, it is presented that a regulating station with the flow of $10000 \mathrm{Nm}^{3} / \mathrm{h}$, the pressure regulators and gas expanders are used in regulation system respectively, with the same inlet temperature and outlet temperature of regulating station, due to the output mechanical work, the heating load of natural gas is much more mass and it's almost 3 times than heat load of regulators, when the gas expanders be used in system(assuming the isentropic efficiency of gas expanders always be $60 \%$ under different flow).In addition, in the case of a certain pressure of inlet natural gas, with the decrease of the pressure of the outlet, the reduction rate of heating load by gas expander method is faster than the pressure regulator method. From Figure 4 we can see, with the increasing flow of natural gas, heat load sharp increase by gas expander method, however, by pressure regulating method, the heat load increases slowly, and with the decreasing of the outlet gas pressure, the heat load be used in heating gas is increasing sharply.

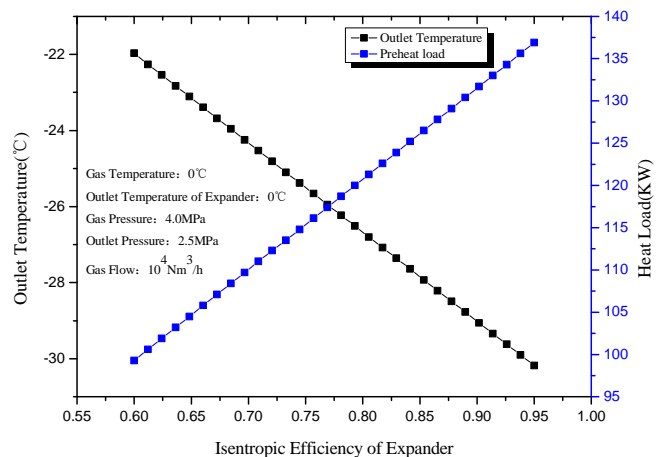

Fig. 6 Variation of the heat load and the outlet temperature of gas with the isentropic efficiency of the gas expander gas.

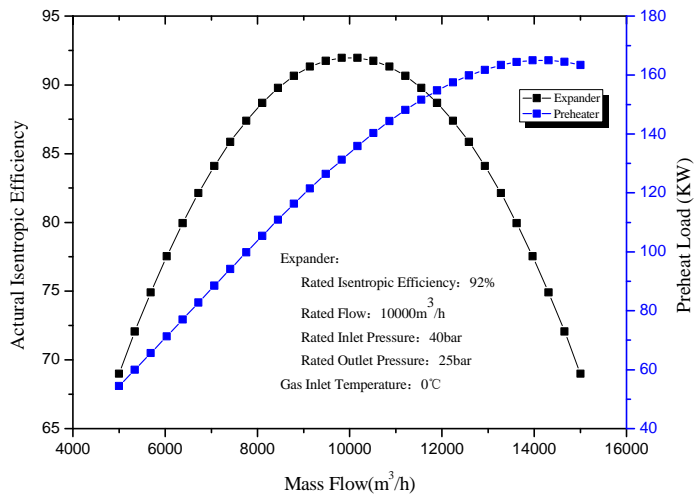

Fig. 7 Effect of natural gas flow on the efficiency and heat load of turbine gas expander

Because of the different types of gas expander with different isentropic efficiency, such as isentropic efficiency of the turbine gas expander can reach above $90 \%$, but it is only about $60 \%$ for the screw gas expander. From Figure 6 it can be seen that the heating load of the screw gas expander is $99.3 \mathrm{KW}$ with the isentropic efficiency of $60 \%$, and with the increasing of the isentropic efficiency, heat load will increase sharply ; when we use the turbine gas expander with the isentropic efficiency of $92 \%$, heat load increases to $134 \mathrm{KW}$, which is increasing about $35 \%$ comparing with the screw gas expander; And the outlet temperature of turbine gas expander is nearly linear decreasing with the increase of the isentropic efficiency.

For a determined type of gas expander, the actual flow of natural gas will have a great influence on the isentropic efficiency of the gas expander. For a TG type turbine gas expander, it runs under the rated inlet pressure is $40 \mathrm{bar}$, and the outlet pressure is $25 \mathrm{bar}$, the rated flow $10000 \mathrm{~m}^{3} / \mathrm{h}$, we can get the formula of isentropic efficiency. 


$$
\eta=\left[\frac{2 V}{V_{d e}}-\left(\frac{V}{V_{d e}}\right)^{2}\right] \eta_{d e}
$$

In the formula, $V_{d e}$ is rated natural gas flow of turbine gas expander $\left(\mathrm{m}^{3} / \mathrm{h}\right)$; $\mathrm{V}$ is the actual natural gas flow of turbine gas expander $\left(\mathrm{m}^{3} / \mathrm{h}\right) ; \eta_{d e}, \eta$ are rated efficiency and actual efficiency of turbine gas expander respectively.

It is calculated the preheat load of the turbine gas expander according to the characteristic curve of isentropic efficiency, which shows in Figure 7. It can be seen from the Figure 7 that, with the increasing of natural gas flow, the isentropic efficiency will increase first and then it will decrease, the heat load used in preheat natural gas is nearly rise perpendicularly in initial stage, the maximum heat load appears when actual flow of gas is $14000 \mathrm{~m}^{3} / \mathrm{h}$, there is a clear downward trend of the heat load will when actual flow of gas reaches $15000 \mathrm{~m}^{3} / \mathrm{h}$. Comparing the preheating load curves between Figure 7 and Figure 5, there is an obvious upward on the curve of the preheating load in Figure 7. This is mainly due to the existence of an irreversible throttling effect in the gas expander, and cause the actual isentropic efficiency is lower than rated isentropic efficiency, and the more actual flow than the rated flow, the more obvious throttling effect in gas expander. This shows that the preheating load increasing nearly linear with the flow of natural gas when actual flow little than the rated flow; It is a downward trend although it is a small extent when the actual flow more than the rated flow for a determined type of turbine gas expander.

\section{Conclusions}

It can be conclude that by establishing numerical model for the system of the urban natural gas pressure regulating station, and analyze the problem caused by a gas expander is employed to replace some regulators to recovery pressure energy.

The main results are as follows:

(1) The analysis of the pressure regulating system consist of the preheater, the pressure regulators and the gas expander, establishing numerical model for the pressure regulating system based on gas expander;

(2) With the decreasing of the gas outlet pressure, the results about outlet temperature of natural gas shows that the outlet temperature is linear decreasing and difference in temperature between outlet and inlet is linear increase no matter how for the gas expander or pressure regulator, but it is faster in outlet temperature drop of gas expander and the difference in temperature between outlet and inlet than pressure regulator, which means that the temperature drop faster caused of the output mechanical work by gas expander, and it also cause the aggravate formation of natural gas hydrate , leads to freezing and blocking the pipelines and equipments, so it must increase inlet temperature by preheating or to use dry method to dry natural gas to reduce the water content of natural gas;

(3) Calculation of natural gas preheating heat load shows that, under the condition of the same gas inflow temperature and outlet temperature in pressure regulating station, the preheating load by using gas expander much is much more than that by pressure regulator; With the increase of outlet pressure or gas flow, preheating load increase rate of the gas expander method is far above faster than that by pressure regulator; The preheating load is increasing sharply with the increase of the isentropic efficiency; The preheating load increasing nearly linear with the flow of natural gas when actual flow little than the rated flow; It is a downward trend although it is a small extent when the actual flow more than the rated flow for a determined type of turbine gas expander.

\section{Acknowledgement}

The authors wish to acknowledge the support provided by the National Natural Science Foundation of China (NO.51206004), the Beijing Natural Science Foundation (NO. 3151001) and the Beijing Key Laboratory of Heating, Gas Supply, Ventilating and Air Conditioning Engineering, Beijing University of Civil Engineering and Architecture. 


\section{References}

[1] Wang Songling, Lun Liyong, Xie Yingbai, Cui Honggang. Combined Cycle System Concept for the Recovery of Pressure Energy of a Natural-gas Pipe Network[J]. Journal of Engineering for Thermal Energy \&Power .-2005 , 20(6): 628-631(In Chinese)

[2] Lun Liyong, Xie Yingbai , Yang Xianliang . LNG peak-shaving proposal based on ressure energy recovery of pipe gas[J]. Natur.Gas Ind, 2006.26(7):114-116(In Chinese)

[3] Li Xiaxi, Jing Yazhou, Gao Min, Wang Shuo, Han Lixin, Yan Lin, et al. Research and Application Prospect Analysis of Power Generation Potential of Beijing Pressure Energy of Natural Gas Pipe Networks[J]. Urban Gas, 2014, (10):10-15. (In Chinese)

[4] GUO Wei, SUN Youhong, ZHANG Zupei, CHEN Chen. The technology of sampling for gas Hydrates by hole bottom freezing[J]. Exploration Engineering(Rock \& Soil Drilling and Tunneling, 2009 supplement: 147-151(In Chinese)

[5] Shahnazar S, Hasan N. Gas hydrate formation condition: Review on experimental and modeling approaches[J]. Fluid Phase Equilibria, 2014, 379: 72-85.

[6] Liu JY, Zhang J, Liu YL, Zhang J. Experimental and Modeling Studies on the Prediction of Gas Hydrate Formation[J]. Journal of Chemistry, 2015, 2015.

[7] Fattah KAA. Evaluation of empirical correlations for natural gas hydrate predictions[J]. Nafta, 2004, 55(11): 467-472.

[8] Mei DH, Liao J, Yang JT, Guo TM. Experimental and modeling studies on the hydrate formation of a methane + nitrogen gas mixture in the presence of aqueous electrolyte solutions[J]. Ind.Eng.Chem.Res, 1996, 35.

[9] Fan SS, Chen GJ, Ma QL, Guo TM. Experimental And Modeling Studies On The Hydrate Formation Of Co2 And Co2-Rich Gas Mixtures[J]. Chemical Engineering Journal, 2000, 78(2):173-178.

[10]Shi Xinyu, Gao Wenjin, Shen Zhenping. Overview of research on natural gas pressure reducing power generation system[J]. China Petroleum Machinery, 2011.39(Supplement):124-126(In Chinese)

[11]HOWARD C. Hybrid Turbogas expander and Fuel Cell System for Power Recovery at Natural Gas Pressure Reduction Stations[D]. Canada: Queen's University, 2009

[12]Neseli MA, Ozgener O, Ozgener L. Energy and exergy analysis of electricity generation from natural gas pressure reducing stations[J]. Energy Conversion and Management, 2015,93:109-120

[13]Farzaneh-Gord M, Arabkoohsar A, Deymi Dasht-bayaz M, Machado L, Koury RNN. Energy and exergy analysis of natural gas pressure reduction points equipped with solar heat and controllable heaters[J]. Renewable Energy, 2014,72:258-270

[14]Kostowski WJ, Usón S, Stanek W, Bargiel P. Thermoecological cost of electricity production in the natural gas pressure reduction process[J]. Energy, 2014, 76: 10-18.

[15]Farzaneh-Gord M, Khatib M, Deymi-Dashtebayaz M, Shahmardan M. Producing electrical power in addition of heat in natural gas pressure drop stations by ICE[J]. Energy, Exploration \& Exploitation, 2012, 30(4): 567-588.

[16] Andrei I, Valentin T, Cristina T, Niculaed T. Recovery of Wasted Mechanical Energy from the Reduction of Natural Gas Pressure[J]. Procedia Engineering, 2014, 69(1):986-990.

[17]Chen Yang. Theory Analysis and Calculation of Natural Gas Pressure Recovery Electricity[J]. Gas Tu r bine Technology, 2013,26(3):65-68(In Chinese) 
[18]Diao Anna, Xu Qiongyan, Zhang Quanming,Wang Yu. Development and application of natural gas screw gas expander[J]. Chemical Engineering of Oil \& Gas, 2013,42(4):378-381(In Chinese)

[19]Lyu Da. Technological Development and Engineering Design of Nature Gas Pipe Network Pressure Energy in Cogeneration[D]. Guangzhou: South China University of Technology, 2013(In Chinese)

[20]An Chengming. Technological Development and Applied Research of Nature Gas Pipe Network Pressure Energy in Power Generation and Ice Making[D]. Guangzhou: South China University of Technology, 2013(In Chinese)

[21]http://www.nist.gov/srd/thermo.cfm 